\title{
Simulação de sintomas e transtornos mentais: Uma revisão crítica do fenômeno para a psicologia
}

Diego Bezerra Rodrigues. Universidade Federal da Paraíba. Géssica Almeida de Freitas. Universidade Federal da Paraíba. Arethusa Eire Moreira de Farias. Universidade Federal da Paraíba. Carmen Amorim-Gaudêncio. Universidade Federal da Paraíba.

\section{Resumo}

A "arte de simular" com objetivo de obter ganhos tem se inserido em diversos contextos, desde situações do dia-dia até processos cíveis e criminais. É difícil delimitar fatores para definir sua presença, manifestando-se como um contínuo. Assim, sua avaliação consiste identificá-la como um fenômeno complexo, multidimensional e multifacetado que requer abordagem biopsicossocial. Ou seja, é um tema que requer atenção de todos os profissionais que lidam com ele. O presente estudo objetiva uma revisão crítica da literatura disponível sobre o problema na área da Psicologia. Realizou-se uma pesquisa nas principais bases de produção acadêmica utilizando os verbetes: "simulação", "sintomas" e "transtornos mentais". Encontrou-se 508 publicações, porém, somente 20 publicações atenderam os critérios de relevância. Neste sentido, é notória a escassez de publicações na área e pouca visibilidade do tema, principalmente no Brasil. Torna-se imperativo que esse tema seja mais pesquisado e que conquiste espaço na formação e na prática do psicólogo devido a sua importância e consequências.

Palavras-chave: psicologia jurídica; simulação de sintomas; avaliação psicológica.

\begin{abstract}
Symptoms and mental disorders simulation: A critical revision of the phenomenon for psychology. The "art of simulating" in order to obtain advantages can be found in various contexts, from day to day situations to civil and criminal cases. Its prevalence varies according to the context and type of simulation, with higher rates in the prison context. It is difficult to delineate specific factors to define its presence, manifests itself as a continuum, and it is necessary to recognize the various scenarios where it occurs. The evaluation is a complex, multidimensional and multifaceted phenomenon that requires a biopsychosocial approach. The aim of this study was a critical review of the available literature on the subject in the area of psychology. Was conducted a survey in major academic production bases using the entries: "simulation", "symptoms" and "mental disorders". It was found 508 publications; however, only 20 publications met the relevancy criteria. Considering this, there are very few publications in the area and a little visibility for this theme, especially in Brazil. It is imperative that this theme be further researched, conquering space in the formation and in the psychologist's practice because of its importance and consequences.
\end{abstract}

Keywords: legal psychology; symptoms simulation; psychological evaluation.

\section{Resumen}

Simulación de síntomas y trastornos mentales: una revisión crítica del fenómeno de la psicología. El "arte del engaño" con fin de obtener ganancias se ha insertado en varios dominios, desde situaciones del día a día hasta los procesos civiles y criminales. Es difícil identificar los factores específicos para delimitar su presencia. Manifiestase en un continuo, siendo necesario reconocer los diferentes escenarios donde el mismo ocurre. Así, su evaluación consiste en la identificación de un fenómeno complejo, muldimensional y multifacético que requiere un abordaje biopsicosocial. En este sentido, la ausencia de tal práctica y su realización cuidadosa constituyese en un desafío y un recto para todos que trabajan con el fenómeno. Este artículo tiene como objetivo hacer una revisión crítica de la literatura disponible sobre el tema en Psicología. Se ha realizado una búsqueda en las principales bases de producción académicas utilizando las entradas: "simulación", "síntomas" y "trastornos mentales". Encontraranse 508 publicaciones, sin embargo, sólo 20 de las encontradas cumplían los criterios de pertinencia. Así, hay pocos estudios en el área y baja visibilidad, especialmente en Brasil. Es imprescindible que este asunto sea investigado más profundamente y conquiste espacio en la formación y la práctica del psicólogo debido a su importancia y consecuencias.

Palabras clave: psicología jurídica; simulación de síntomas; evaluación psicológica. 
Estudar e entender o fenômeno da simulação requer uma visão histórica que considere tanto o comportamento humano e animal. O fenômeno de simulação é comum entre os animais; alguns artrópodes fingem-se de morto (tanatose), várias aves emitem sons parecidos ao de outros animais, determinados répteis simulam ferimento ou procuram se camuflar de acordo com o ambiente ou se disfarçam de outros seres para enganar os seus predadores (Felipe, 2007; Souza, no prelo). Esses comportamentos são chamados de antipredatórios por funcionarem como uma estratégia de sobrevivência, contribuindo para a evolução de muitas espécies (Felipe, 2007; Teixeira, 2012).

$\mathrm{Na}$ história da humanidade a simulação foi representada em fatos mitológicos da Grécia Antiga, dizia-se, por exemplo, que durante a guerra de Tróia, Ulisses fingiu-se de louco e pôs-se a arar as areias do mar, quando foi reconhecido por Pelamedes, que denunciou o seu disfarce (Jorge \& Jorge, 2011).

Ao longo da história a simulação esteve presente no comportamento de soldados, marinheiros e prisioneiros de guerra que fingiam-se de doentes ou de mortos para conseguirem dispensa dos serviços militares ou mesmo para fugir dos deveres cívicos (Jorge \& Jorge, 2011; Taborda, Chalub, \& Abdala-Filho, s/d). A partir do séc. XX houve uma crescente publicação referente ao tema da simulação na medicina, mas sem especificar seus sinais e sintomas e sem consenso acerca do seu conceito (Jorge \& Jorge, 2011; Souza, no prelo). Contudo, a pesquisa sobre a "pseudohypoacusis" ou condição de aparente perda de audição na ausência de evidência clínica ou audiológica vem chamando a atenção dos especialistas como um caso típico de simulação e encontrando apoio empírico (Boedler \& Rogers, 1989). O problema é visto como um fenômeno psicossocial e para a sua avaliação a figura do psicólogo é considerada fundamental.

Como pode ser percebido, o comportamento de simulação de sintomas atravessa diferentes contextos como o da saúde (medicina, enfermagem, psicologia e fonoaudiologia), o do direito penal e penitenciário e da previdência social (Andrade \& Azevedo, 2006; Jorge \& Jorge, 2011; Pereira, 2012). Alguns autores (Aliaga, Arch, García-Molina, \& Jarne, 2013; Jorge \& Jorge, B., 2011; Pereira, 2012; Taborda et al., s/d) chamam a atenção à necessidade de se reconhecer métodos e técnicas de avaliação e diagnóstico mais precisos.

O estudo da simulação das enfermidades e da loucura, assim como sua detecção, é de grande importância para o cumprimento adequado de infrações e para a execução de penas (Altavilla, 2007). Dessa forma, o indivíduo simulante ao pretender a obtenção de alguma vantagem para si, no seu processo de avaliação/perícia, procura fazer uso de algum subterfúgio comportamental que transpareça alguma invalidez ou algum transtorno mental para o seu avaliador/perito e, assim, faz de tudo para enganar e manipular os resultados (Altavilla, 2007; Taborda, et al., s/d).

No contexto forense e criminal, a simulação é um comportamento a ser considerado nos processos de avaliações e perícias (Pereira, 2012; Taborda et al., s/d). O psicólogo, a avaliação realizada e o parecer resultante são decisivos nos processos judiciais já que envolvem avaliação de incapacidades, podendo também constituir um elemento atenuante de pena (Paulo, 2012).

A fim de ressaltar a importância da simulação para a psicologia e promover sua discussão, realizou-se uma revisão crítica da literatura sobre os conceitos, a detecção e as principais características do comportamento da simulação de sintomas relacionados a transtornos mentais a partir de pesquisa nas principais bases de dados da produção acadêmica (artigos, periódicos, trabalhos de conclusão de curso, teses e dissertações), além de capítulos de livros e demais fontes bibliográficas.

\section{Método}

Para a realização dos objetivos estabelecidos os autores fizeram uma busca ${ }^{1}$ nas bases de dados acadêmicos Lilacs (http://lilacs.bvsalud.org/), Scielo (http://www.scielo.br/), PEpsic (http://pepsic.bvsalud. org/), Indexpsi (http://newpsi.bvs-psi.org.br/), banco de teses da USP e da CAPES (http://www.teses.usp.br/e http://bancodeteses.capes.gov.br/) e google acadêmico (https://scholar.google.com/); utilizando os verbetes: "simulação", "sintomas" e "transtornos mentais".

\section{Resultados e discussão}

A partir da pesquisa nas bases já mencionadas, foram identificadas 508 publicações variando entre artigos, resumos, periódicos, TCCs e dissertações. Ao filtrar as publicações em português e espanhol, identificaram-se oito artigos em LILACS e 493 em Google acadêmico. Os autores consideraram, além das fontes eletrônicas, livros e capítulos de livros que dispunham do tema.

Posteriormente à realização da pesquisa nas bases, deu-se início a leitura dos resumos em português 
dos artigos eletrônicos. Foram desconsideradas as publicações repetidas, publicadas em mais de uma base e as que não tinham relação com os objetivos específicos deste estudo. Para a fundamentação deste artigo foram utilizadas 20 publicações: seis artigos; cinco livros, seis dissertações e três trabalhos de conclusão de curso. A escolha por essas publicações se deu pela criação de critérios de relevância dos autores, a saber: discussão conceitual, a relação de comportamento de simulação com transtornos mentais, avaliação psicológica e perícia.

Com base nas pesquisas e na leitura das demais referências bibliográficas encontradas, organizou-se a discussão sobre o tema em cinco categorias teóricas: Conceitos e definições sobre de Simulação; Contextos de inserção da simulação de sintomas; Prevalência da simulação de sintomas; O Diagnóstico Diferencial; e os Principais Sintomas e Transtornos Mentais Simulados.

\section{Conceitos e Definições de Simulação}

As pesquisas indicam um interesse atual sobre o problema da simulação através de relatos de pesquisa, estudos de casos e revisões da literatura. Foi possível destacar uma tendência de vários centros de pesquisa de favorecer o desenvolvimento de novos estudos sobre a temática, colaborando com profissionais e pesquisadores em diversas áreas em que comportamentos simulados se revelem, favorecendo ao mesmo tempo a discussão acadêmica. Tamanho interesse é alertado por Gonçalves (2012) pela prevalência e o aumento dos sujeitos simuladores, sendo importante uma continuidade na investigação empírica desse tipo de comportamento para realmente conhecer a dimensão do problema e suas consequências.

No Dicionário de Psicologia (Mesquita \& Duarte, 1996, p.187), o conceito de "simulação de enfermidades" aparece como uma atitude consciente de simular uma doença com ou sem um objetivo preciso. Essa mesma atitude, consciente ou intencional, associada ao controle da situação da perícia criminal foi observada por Taborda et al. (s/d, p. 471). Assinala-se a necessidade de utilização de um procedimento que favoreça a identificação um conjunto de sinais e sintomas que seja reconhecido e convença o médico ou o examinador de uma situação que o periciado deseja para si. Para esses autores, a simulação é a "arte do engano".

Sobre as características do comportamento da simulação, Gonçalves (2012, p. 43) destaca algumas características de personalidade e do estado mental do sujeito simulador, como: relações afetivas com pouco investimento ou falseadas, postura manipuladora, facilidade de assumir vários papéis, utilização de comportamentos falsos, facilidade e fluidez verbal, desenvolvimento empático hipertrofiado, sentido de realidade exacerbado, porém paradoxal e possível envolvimento com conversas esotéricas ou artificiais.

No DSM-V, a simulação se faz presente no capítulo de "Outras Condições que Podem Ser Foco da Atenção Clínica". Nesse manual a simulação é conceituada como a produção intencional ou grosseiramente exagerada de sintomas físicos ou psicológicos falsos, motivados por incentivos externos, recompensas ou para evitar responsabilidades, podendo ser considerado um comportamento adaptativo em situações de perigo (fingir doença em um sequestro) (Associação Brasileira de Psicologia [ABP], 2013, p. 766).

Aconselha-se ainda suspeitar de simulação quando as seguintes condições estiverem presentes: contexto médico-legal; discrepância entre o sofrimento, a incapacidade referida e os dados obtidos; falta de colaboração na avaliação diagnóstica e não adesão ao tratamento; presença de personalidade antissocial (ABP, 2013). Essas circunstâncias são essenciais na identificação da simulação; o ganho da causa específica e a intencionalidade momentânea de apresentar tais comportamentos que não são encontrados em outras circunstâncias da vida do paciente ou periciando.

Cabe considerar que o comportamento de simulação também é uma característica relacionada ao Transtorno Factício e está no capítulo de "Transtornos de Sintomas Somáticos e Transtornos Relacionados". Os sinais e sintomas desse transtorno consistem na falsificação de sinais e sintomas médicos em si mesmo ou em outro (Transtorno Factício por procuração ou Imposto a outro) visando assumir, ou atribuir ao outro, o papel de doente ou incapacitado por alguma situação.

Nesse transtorno, a simulação é representada pelo exagero de doenças existentes, a simulação e produção de sintomas (lesões fraudulentas, mutilação, manipular resultados exames, etc.). Os cuidadores de pessoas atribuídas com transtorno factício podem se deparar com mentiras que não podem ser explicadas pelo quadro clínico e pelas informações colocadas nos prontuários.

Pessoas com esse diagnóstico são consideradas com grande sofrimento psicológico e possíveis prejuízos quanto ao seu estado mental, podendo ser um risco para si e para pessoas a sua volta (ABP, 2013). Quanto ao Transtorno Factício, o DSM V limita-se apenas ao 
diagnóstico, ou seja, a identificação dos sinais e sintomas sem inferir na possível a motivação do sujeito não apresentando modelos de tratamento.

Tanto a Simulação quanto o Transtorno Factício são citados na maioria dos itens "Diagnóstico Diferencial" no final dos principais transtornos mentais presentes no Manual, inferindo a importância de considerar a simulação antes de fechar o diagnóstico de alguém. A diferenciação entre Simulação e o Transtorno Factício, de acordo com o DSM-V está nas motivações que os sujeitos manifestam. No caso da Simulação, a motivação ou os incentivos são externos mostrando uma recompensa óbvia, por exemplo, uma situação de avaliação ou perícia ou a necessidade de ser dispensado. No caso do Transtorno Factício, a motivação é interna e muitas vezes não está explícita (ABP, 2013; Sadock \& Sadock, 2012).

De acordo com Sadock e Sadock (2012) a epidemiologia do comportamento de simulação de sintomas é desconhecida, porém destacam uma maior preponderância dos homens sobre as mulheres em ambientes como forças armadas, penitenciárias, fábricas e indústrias. Os sinais e sintomas a serem observados quando há a suspeita de simulação que foram classificados por esses autores são: queixas indefinidas ou mal localizadas, explicadas com detalhes, histórico psicossocial que revela necessidade de ajuda para receber benefícios ou ganhos secundários (indenizações), evitar uma situação relacionadas a problemas legais e irritabilidade se o médico se mostra cético a sua queixa (Sadock \& Sadock, 2012).

No Código Internacional de Doenças (CID-10), o comportamento de simulação está presente em três códigos ou classificações. O primeiro aparece no capítulo V: Transtornos Mentais e Comportamentais com o código F68.1 relacionado ao transtorno factício com a seguinte conceituação: "Produção deliberada ou simulação de sintomas ou de incapacidades físicas ou psicológicas"; O segundo e terceiro código é encontrado no capítulo XXI: Fatores que Influenciam o Estado de Saúde e o Contato com Serviços de Saúde apresentando a Simulação Consciente com o código Z76.5 "pessoa fingindo ser doente" e, em seguida, o código Z76.9 especifica "pessoa em contato com serviços de saúde em circunstâncias não especificadas". Neste último código, embora não especificado, que foi destacada por Taborda et al. (s/d) como uma outra abertura para suspeita da simulação (Organização Mundial da Saúde [OMS], 1998).

Apesar dessas especificações que caracterizam o comportamento de simulação, vale ressaltar que pode haver indivíduos que realmente apresentam doenças que afirmam em seu discurso ou sofrimento. Por esta razão, os manuais propõem alguns elementos para o diagnóstico diferencial cuidadoso a serem seguidos pelos profissionais de saúde. Apesar disso, Soares (2013) defende que os critérios colocados pelos manuais são muito amplos e que podem levar a diagnosticar uma pessoa idônea como simuladora e, consequentemente, aliená-la de seus direitos.

Pode-se ver que entre essas definições de simulação, há uma preponderância à observação da intencionalidade e dos motivos conscientes e externos para a criação de sinais que possam levar ao perito a acreditar que o periciado é portador de alguma patologia, fazendo com que este seja liberado de suas responsabilidades (legais, criminais) ou forjando ganhos secundários (indenização, soltura, dispensa do serviço militar).

Entre outras classificações, Resnick (citado por Taborda et al., s/d, p. 472) identifica subcategorias de simulação: 1) a simulação pura; 2) a simulação parcial; e 3) a falsa imputação. A Simulação Pura ocorre quando a pessoa simula um transtorno que não existe, sendo a mais recorrente em contextos criminais; a Simulação Parcial ocorre quando a pessoa exagera conscientemente os próprios sintomas, comuns em avaliações clínicas e causas civis; a Falta de Imputação ocorre quando a pessoa atribui sintomas de forma intencional, isso acontece sem relação com a etiologia do desenvolvimento desses.

Taborda et al. (s/d, p. 472) construíram a sua própria classificação de simulação, dividindo-as em supersimulação, metassimulação, pré-simulação e dissimulação. A supersimulação é caracterizada por ser o exagero de sinais e sintomas de uma pessoa enferma ou criação de novos sintomas; a metassimulação ocorre depois da cura da enfermidade em que o paciente continua mostrando-se de doente, nessa, a pessoa já teria aprendido quais sintomas simular; a pré-simulação, ou simulação premeditada, é uma condição planejada de criação de sintomas, mas esses carecem de identidade diagnóstica; a dissimulação consiste em ocultar ou minimizar uma doença ou transtorno existentes.

Contudo, é preciso ir além da definição e do embate conceitual sobre a simulação. $O$ processo de avaliação da simulação dos sintomas, assim como a pesquisa sobre o tema, deve ser considerado no cotidiano dos profissionais, colaborando para que processo de avaliação seja mais idôneo e congruente com os aspectos éticos e legais preconizados na formação e nos códigos profissionais. 


\section{Contextos de Inserção da Simulação}

A arte de simular pode estar inserida em diversos âmbitos, desde situações corriqueiras do dia a dia e alcançar processos cíveis e criminais. Nos últimos anos tem crescido o interesse dos pesquisadores com grande número de publicações concentradas em indivíduos que recorrem a afirmações falaciosas no sistema médico-legal (Taylor, Frueh, \& Asmundson, 2007 citado por Pereira, 2012), em decorrência da facilidade de altas tentativas de forjar os seus desempenhos nas avaliações ou perícias realizadas pelos profissionais (Bush et al., 2005; Vitacco, Rogers, Gabel, \& Munizza, 2007; Vitacco et al., 2008 citados por Pereira, 2012). Isso acarreta no aumento significativo de solicitações de atuações dos profissionais de psicologia, pelo menos em contextos internacionais já que a atuação dos psicólogos nesse tipo de avaliação se resume ao emprego da avaliação psicológica e especificamente a testagem psicológica. Neste âmbito, estes devem se pronunciar, enquanto peritos, sobre a credibilidade dos examinados que dizem possuir déficits cognitivos, queixas emocionais e/ou posturas defensivas e protetoras (Simões, 2006 citado por Pereira, 2012).

$\mathrm{Na}$ esperança de obter compensações secundárias e/ou atenuar as condenações, é consensual que a população que se encontra reclusa tem mais tendência para simular sintomas de forma a justificar o passado criminal, sendo frequente encontrar simulação no desempenho de testes (Simões, 2010 citado por Costa, Espirito-Santo, Matreno, Fermino, \& Amaro 2012).

Simões et al. (2010 citado por Costa et al., 2012) afirmam que também é possível observar um aumento da simulação nas avaliações psicológicas em contextos de litígio, e os ganhos secundários, aponta-se como a principal razão para que este fenômeno aconteça (LeesHaley \& Dunn, 1994; Ruiz, Drake, Marcottee, Glass, \& Gorp, 2002; Steffan, Clopton, \& Morgan, 2003 citados por Gonçalves, 2012).

A questão da credibilidade das alegações no âmbito das responsabilidades parentais é de extrema importância, uma vez que pode trazer fortes implicações para a vida dos progenitores e, acima de tudo, para a vida de crianças e/ou adolescentes, como exemplo pode-se citar a questão da guarda conjunta (Austin, 2000 citado por Pereira, 2012), nomeadamente em casos de violência (Newmark, Harrell, \& Salem, 1994; Straw, 1979 citados por Pereira, 2012). Neste sentido, uma avaliação da simulação pouco criteriosa pode ter consequências negativas substanciais para a vida pessoal e familiar do examinado.
Nesta área dos processos cíveis, também há relatos de casos relacionados com acidentes de trabalho que se apresentam como uma parcela considerável na avaliação da simulação, uma vez que são, usualmente, altamente litigiosos (Simões \& Sousa, 2011 citado por Paulo, 2012). E ainda há casos na população militar, em que a avaliação da simulação se revela particularmente importante devido ao grande número de pedidos de compensação ou dispensa de serviço militar, após algum tipo de lesão sofrida pelo militar no decorrer do serviço (Lange, Pancholi, Bhagwat, Anderson-Barnes, \& French, 2012 citado por Paulo, 2012).

Faz-se necessário esclarecer que os ganhos secundários podem ser inúmeros, como incentivos de natureza financeira, redução de penas, alteração nas condições de trabalho, ter acesso a fármacos, indenizações, evasão de responsabilidades e ameaça de punição ou retaliação, e podem acarretar um declínio de desempenho, nomeadamente, em casos de avaliação da competência para testemunhar, de exame das sequelas de um acidente, de processos de responsabilidades parentais e de pedidos de reforma antecipada (Teichner \& Wagner, 2004; Simões \& Sousa, 2008; Simões et al., 2010 citados por Pereira, 2012).

O fato de a simulação estar presente nos diversos espaços e com aumentos consideráveis, é no mínimo curioso. Uma vasta literatura indica como sendo uma possível explicação para o fenômeno o fato da informação sobre qualquer temática, incluindo a psicologia (por exemplo, sintomas dos transtornos e síndromes neuropsiquiátricas) estar cada vez mais acessível à população (Lees-Haley \& Dunn, 1994; Ruiz et al., 2002; Steffan et al., 2003 citados por Gonçalves, 2012). Victor e Abeles (2004 citado por Gonçalves, 2012) afirma que tal fato leva até advogados a sugerirem aos seus clientes que evidenciem determinados sintomas e comportamentos simulados.

Devido à ampla gama de decisões judiciais que pode advir da avaliação da validade das respostas, do esforço e da realização de relatórios, avaliações cuidadosas se fazem necessárias e urgentes em todos os âmbitos que a simulação pode estar inserida, uma vez que envolvem uma série de questões cíveis, criminais e familiares (Conroy \& Kwartner, 2006; Heilbronner et al., 2009; Melton, Petrila, Poythress, \& Slobogin, 1987, citados por Pereira, 2012).

Por outro lado, percebe-se que a simulação é ainda algo situacional, ou seja, a simulação de sintomas, por parte de determinado sujeito, é usualmente restrita 
ao contexto ou situação, não devendo este sujeito ser visto como desonesto ou censurável (Tombaugh, 1996 citado por Paulo, 2012). Como explicita Iverson (2003 citado por Paulo, 2012) quase todo indivíduo, ao longo da vida, um dia já simulou algum sintoma, por exemplo, para faltar ao trabalho ou à escola.

\section{Prevalência da Simulação}

Simões et al. (2010 citado por Gonçalves, 2012) referem que a prevalência de sujeitos simuladores tem aumentado, e que por isso, são necessários mais olhares sobre este tipo de atitude.

A prevalência da simulação varia de acordo com o contexto (O'Bryant \& Lucas, 2006; Heilbronner et al., 2009; Hilsabeck, Gordon, Hietpas-Wilson, \& Zartman, 2011; McDermott, Dualan, \& Scott, 2013 citados por Soares, 2013) e tipo de simulação considerado (Mittenberg, Patton, Canyock, \& Condit, 2002 citado por Paulo, 2012), existindo indicações de que a prevalência de comportamentos associados à simulação é substancialmente elevada em contexto prisional (Scott, McDermott, Bobb, \& Reid, 2012 citado por Soares, 2013).

Vários estudos que analisaram comportamentos de simulação em contexto prisional centraram-se no exagero de sintomas (McDermott \& Sokolov, 2009; McDermott et al., 2013; Pollock, 1997; Pollock, Quigley, Worley, \& Bashford, 1997; Norris \& May, 1998; Walters, 2011; citado por Soares, 2013, citados por Soares, 2013), tendo sido encontrados valores entre os $32 \%$, numa amostra proveniente de uma prisão de média segurança (Pollock et al., 1997 citado por Soares, 2013) e os 45$56 \%$, dependentemente do instrumento utilizado, numa amostra de reclusos que relataram solicitaram serviços de consulta psicológica (Norris \& May, 1998 citado por Soares, 2013). E pesquisas mais recentes (McDermott \& Sokolov, 2009; McDermott et al., 2013 citados por Soares, 2013), verificaram prevalências de comportamentos de simulação de $64.5 \%$ e $66.5 \%$ em amostras de reclusos que procuraram serviços psiquiátricos. No entanto, estes números podem ter sido inflacionados pelo fato de apenas os reclusos, previamente apontados como suspeitos de simulação, terem sido submetidos à avaliação (Soares, 2013).

Merckelbach, Smeets e Jelici (2009 citado por Gonçalves, 2012) apontam que cerca de 13 a $29 \%$ de probabilidades de um sujeito falsear sintomas numa perícia de avaliação psicológica e para casos de avaliação de personalidade se encontra entre 17 a $19 \%$ de tentar enganar o avaliador.
Como foi visto, embora seja difícil existir uma taxa de simulação concisa, outros estudos indicam que tal comportamento pode variar entre 15 a 17\% (Rogers \& Bender, 2003; Conroy \& Kwartner, 2006 citados por Pereira, 2012), 21\% (Vitacco et al., 2007; Ray, 2009 citados por Pereira, 2012) e 40\% (Larrabe, 2003 citado por Pereira, 2012).

Slick, Tan, Strauss e Hultsch (2004 citado por Paulo, 2012) realizaram um estudo sobre a simulação de sintomas diferente, pois eram entrevistados os profissionais da área (39), ao invés dos pacientes. Tais profissionais consideravam que durante os últimos 12 meses pelo menos $10 \%$ dos avaliados estariam simulando sintomas.

\section{O Diagnóstico Diferencial: Dificuldades e Possibilidades na Detecção}

Domingues (2012) assevera que é difícil delimitar fatores específicos para se definir a presença da simulação, já que se manifesta em um contínuo, sendo necessário reconhecer os vários cenários onde ocorre. A autora afirma que a avaliação deve ser "conceptualizada como um fenômeno complexo, multidimensional e multifacetado que requer uma abordagem de caráter biopsicossocial" (p. 6).

É importante conhecer a história individual do sujeito, pois a simulação pode estar associada a incentivos externos relacionados à sua vida passada, como: "história de emprego irregular, ausências excessivas ao trabalho; comportamentos de desonestidade arreigados; conhecimento das normas legais relevantes para o seu caso; exposição prévia a processos litigiosos e experiência com companhias de seguro" (Domingues, 2012, p. 5).

A utilização de procedimentos de avaliação psicológica, mais especificamente de seus instrumentos mais conhecidos, os testes, contribui para o enriquecimento da avaliação. No entanto, o uso de uma única medida não é aconselhável, pois o conteúdo e o formato dos testes faz com que sejam melhor aproveitados quando aplicados em conjunto (Domingues, 2012; Paulo, 2012). Portanto, o emprego do processo técnico e científico da avaliação psicológica com todas as suas fases e procedimentos se faz uma condição sine qua non, de outra forma, não há validade criterial que sustente as afirmações que advirão de um processo tão complexo como o da simulação, onde vários fatores entram em jogo. É preciso para este processo o conhecimento da psicopatologia avaliada, as ferramentas de engano utilizadas pelos prováveis simuladores e, 
principalmente, o emprego de instrumentos de avaliação da simulação válidos e fidedignos.

Não obstante, sabe-se que, particularmente em contexto forense, o avaliado encontra-se muitas vezes motivado para simular problemas cognitivos ou para esconder e distorcer o seu funcionamento psicológico. Torna-se, assim, imprescindível medir e controlar até que ponto os resultados obtidos se devem às competências reais do indivíduo, à sua motivação externa ou até ao esforço que este empenhou na realização dos testes (Paulo, 2012).

Os instrumentos construídos para avaliar a simulação de sintomas procuram mostrar em que medida estes comportamentos são realmente válidos, falsos ou exagerados (Simões, 2006 citado por Paulo, 2012). Existem diversos métodos para despistar a simulação de sintomas com diferentes graus de eficácia. Enfatiza-se que para além de aplicação de instrumentos psicométricos, é importante fazer uma avalição qualitativa das respostas do periciado, considerando variáveis contextuais/ situacionais e incoerência no desempenho (Domingues, 2012). Uma análise subjetiva do avaliador, como, por exemplo, a procura de resultados inconsistentes, discrepantes ou que não façam sentido de um ponto de vista clínico e/ou psicométrico pode ser o primeiro passo para analisar uma situação de simulação. No entanto, o caráter subjetivo e impreciso desta avaliação torna evidentes diversas limitações, refletindo assim uma taxa de sucesso de identificação deficitária (Paulo, 2012).

A respeito do uso dos testes, Soares (2013) destaca que embora existam vários TVS (Teste da Validade de Sintomas) disponíveis no contexto internacional, não há consenso relativamente de qual é o "melhor" instrumento na detecção de comportamentos de esforço reduzido e exagero de sintomas. E ainda, neste âmbito, emerge a evidência da necessidade de ajuste dos pontos de corte, sob pena de classificar erradamente estes sujeitos em "simular" ou em "exagerar sintomas" (Pinho, 2012). Neste sentido, apesar de reconhecida a importância dos TVS em situações que não apenas de litígio, o seu uso ainda não é sistemático em contexto de avaliação psicológica e neuropsicológica (Pinho, 2012). Esse problema alcança especificamente o contexto brasileiro, onde a falta de instrumentos forenses específicos é uma triste realidade e outros instrumentos específicos para a avaliação na personalidade estão desatualizados e com parecer negativo do Sistema de Avaliação de Testes Psicológicos - SATEPSI. Neste sentido, inclui-se o MMPI-II-R (Inventário Multifásico Minnesota de Personalidade - 2 - Restruturado) e o MILLON-III (Inventário Clínico Multiaxial de Millon - $3^{\text {a }}$ Versão). O primeiro encontra-se desatualizado e corresponde à versão inicial do instrumento, e o segundo ainda não foi publicado por alguma das editoras nacionais, ainda que já exista uma versão validada para o contexto nacional que vem sendo empregada em pesquisas. Esses instrumentos são utilizados no contexto forense porque ambos possuem escalas de validação e de sinceridade, sendo de grande utilidade para o objetivo da avaliação da simulação de sintomas.

Altavilla (2007) ensina que dificilmente um simulador conhece uma doença mental em sua complexidade e singularidade a ponto de conseguir prever a necessidade de manter uma constância de sintomatologia mesmo antes do crime, fazendo com eles, em sua leiga tentativa de simular uma doença mental, se entreguem pelo simples fato de manifestarem determinados sintomas apenas após o delito sintomas, que, muitas vezes, possuem diversos estágios e que precisam de um longo período para se desenvolver.

Entretanto, o autor instrui ainda que há aqueles criminosos com uma maior capacidade intelectual, sagazes o suficiente para atentar aos detalhes, ou que muitas vezes já passaram por manicômio criminal e tiveram contato com doentes mentais genuínos e conhecem mais profundamente algumas configurações de sintomas. A simulação não é uma tarefa fácil, devido à rigidez da sintomatologia das doenças mentais, o que dificulta a simulação mesmo para o mais rigoroso dos criminosos.

Na pesquisa realizada, foi possível verificar que sete publicações acadêmicas (Altavilla, 2007; Domingues, 2012; Gonçalves, 2012; Paulo, 2012; Pereira, 2012; Pinho, 2012; Soares, 2013) apontam para a importância e necessidade de um observador bem treinado e atento para detectar um simulador, que se entrega nas minúcias.

Consequentemente, a avaliação da simulação é um procedimento fundamental, não apenas nestes casos. No entanto, este procedimento é poucas vezes utilizado, ou é efetuado de forma pouco rigorosa. Assim, observa-se que a ausência de tal prática e de sua realização cuidadosa constitui um desafio e, ao mesmo tempo, uma perspectiva para todos que lidam com o fenômeno. Mas, cabe ressaltar que avaliação psicológica e neuropsicológica ou avaliação psicológica das funções mentais superiores (cognitiva) é considerada como ferramenta imprescindível na identificação do fenômeno (Gonçalves, 2012). 
Como mencionado anteriormente, o conhecimento da psicopatologia se mostra essencial, ajudando na identificação de características que podem não harmonizar-se com o quadro sintomatológico apresentado, permitindo a identificação do simulador. No entanto, na pesquisa bibliográfica realizada pelos autores, foi encontrado apenas um artigo relacionado à temática, e mesmo assim focando-se apenas no transtorno de estresse pós-traumático (Mendlowicz \& Berger, 2011).

Das referências analisadas nesse estudo, Altavilla (2007) em seu livro "Psicologia judiciária: o processo psicológico e a verdade judicial", é o único que apresenta uma lista pormenorizada de sintomas e transtornos mentais mais comumente utilizados pelos simuladores, suas características básicas e as dificuldades enfrentadas pelos periciados em manter a coerência. Deste modo, expõe-se a seguir um breve resumo fundamentado principalmente no referido autor (Altavilla, 2007).

\section{Principais Sintomas e Transtornos Mentais Simulados}

Dentre os principais sintomas e transtornos mentais mais frequentemente simulados encontram-se o estado maníaco, simulação de formas esquizofrênicas, demência, delírio sistematizado, histerismo, estado melancólico, mutismo, epilepsia, amnésia e o delírio ciumento (Altavilla, 2007). Além destes, também foram encontradas na literatura pesquisada algumas menções ao transtorno de estresse pós-traumático (Domingues, 2012; Mendlowicz \& Berger, 2011), optando-se também por incluí-lo nesta categoria, em complemento ao exposto por Altavilla (2007).

No estado maníaco o indivíduo, acometido por uma tumultuosa confusão dos processos psicológicos, fica alheio ao que acontece à sua volta, apenas recolhe alguns fragmentos de percepção, que não conseguem lhe fixar a atenção. Além disso, mantém-se em um estado "elétrico", onde não come nem dorme, emagrecendo no processo.

O simulador se entrega, pois este, atento e interessado no desenrolar do seu processo, acaba por, em determinados momentos, demonstrar raciocínio lógico através de uma frase sensata, ou observação acurada, acontecimento que um sujeito no estado maníaco jamais conseguiria. Ao mesmo tempo, a simulação dessa desordem mental exige enorme esforço, o que requer momentos de repouso, onde o simulador termina por revelar sua falácia, já que o maníaco se mantém ativo o tempo todo.
Os esquizofrênicos caracterizam-se pela dissociação e incoerência, o que faz com a simulação dessas manifestações tenham poucas chances de sucesso. Os simuladores fracassam, muitas vezes, pelo excesso.

A demência se manifesta por uma atitude apática, indiferente, e perturbações na consciência. Encontra-se quase completamente abolida a vida psíquica, que dá lugar a uma fisionomia parada, de um quase bem-estar. Também se evidencia falta de preocupações higiênicas.

No simulador, é possível identificar a sua ansiedade no seu olhar preocupado e ativo, olhar este atento, móvel, sagaz, olhar de alguém que está para ser julgado e tem plena consciência do fato. Além disso, ele se entrega ao conseguir realizar tarefas delicadas que requerem paciência e atenção.

No delírio sistematizado, por mais ilógico que o pensamento possa parecer, ao se adentrar mais profundamente no raciocínio do delirante se pode encontrar juízo e associações de ideias tão lógicas quanto às de alguém normal. $\mathrm{O}$ simulador peca ao tentar se afastar mais e mais das leis lógicas, sem saber que o mais disparatado dos delírios sistematizados possui uma coerência lógica impecável.

O histérico se caracteriza pelo comportamento dramático, a busca constante por atenção e egocentrismo, muito centrado em si mesmo. Mas a problemática maior desse quadro consiste no fato de que a simulação faz parte de sua sintomatologia, o que dificulta o diagnóstico.

Uma forma de se lidar com a problemática consiste em se indagar até que ponto o doente tem consciência de seus sintomas e tenta omiti-los ou evidenciá-los. Enquanto que o doente genuíno faz de tudo para esconder seus sintomas e, assim, evitar o estigma da doença, o simulador faz de tudo para evidenciar o seus.

O estado melancólico apresenta apatia e desinteresse pelas coisas. O melancólico fica de tal modo absorto em uma concentração dolorosa, que se abstrai do mundo à sua volta. Não se trata, contudo, de falta de atenção, porque a atenção está de tal forma presa às ideias predominantes em sua mente que nada mais consegue penetrar na sua consciência. Mas a característica mais saliente desse quadro e da qual, geralmente, os simuladores se valem, é o suicídio.

Os simuladores se deixam descobrir ao tentar emular sintoma tão grave como o suicídio sem levar em consideração a concordância com um quadro complexo que levaria a tão extrema atitude. Além disso, a preparação da cena é feita de forma banal e amadora. 
Outro detalhe que facilmente os entrega são as atitudes defensivas, demonstrando interesse com o desenrolar dos acontecimentos. Postura que um melancólico absorto em seus pensamentos negativos dificilmente apresentaria. É preciso enorme esforço para inibir tais preocupações, e os simuladores acabam por se revelar quando apresentam um plano de defesa durante os interrogatórios.

O mutismo é uma forma que os simuladores encontram de se esquivar das possíveis armadilhas da fala. Enganam-se, porém, ao pensar que se manter calado é tarefa fácil, e que tal atitude é suficiente para se passar por doente mental, já que o mutismo é apenas um elemento de uma configuração sintomatológica mais complexa.

Entregam-se ao apresentar comportamentos contraditórios ao obstinado silêncio. A gesticulação ativa, o olhar lúcido, móvel, indagador, músculos não relaxados nem contraídos, reagindo às circunstâncias exteriores, desmascaram sua vã tentativa de simulação. Além do mais, o doente que se recusa a falar, geralmente, fala sozinho, sussurra, ou ainda responde apenas com sim ou não, diferente do simulador que tenta se manter calado em todas as circunstâncias.

Uma boa estratégia consiste em prolongar o período de observação, ou falar sobre coisas do interesse do simulador em sua presença, pois o cansaço e o fato de que o ser humano é equipado naturalmente para expressar seus pensamentos, fazem com que uma hora ou outra o simulador revele a sua mentira.

No que diz respeito à epilepsia, o que atrai o simulador é a sua característica mais básica, a convulsão. Não sabe, contudo, que a convulsão e a amnésia que se segue, fazem parte de um quadro de fenômenos mais intricado,

(...) não sabe que o ataque é precedido por um grito inicial, um característico grito que anuncia o mal. Não sabe que na queda qualquer instintivo movimento de defesa desaparece, enquanto ele revela a vontade que se mantém alerta para evitar qualquer dano sério. Não pode determinar a asfixia com suas manifestações ejectivas na modificação do circuito sanguíneo e de coloração periférica da cútis; não pode simular as sacudidelas musculares que apresentam um ritmo tónico e clónico ou combinado e interessam os mesmo segmentos do corpo. Ignora que o ataque epiléptico tem consequências psíquicas: contração, estupor, desorientação; não pode produzir as típicas alterações dos reflexos pupilares, os caracteres especiais da urina (Altavilla, 2007, p. 302).
Outro sintoma comumente simulado é a amnésia, mesmo sem a presença de um ataque epiléptico, pois é muito vantajoso não ter que falar sobre o crime, evitando, assim, que se deixe entregar pela fala. No entanto, o amnésico genuíno possui certas características distintas, e o simulador pode ser desmascarado ao se atentar para alguns detalhes.

Primeiro que, para o doente acometido pela amnésia, a lacuna de sua vida de que não consegue se lembrar representa um constante tormento, fazendo que este procure eliminar de qualquer modo, ou procure preencher através do relato de outras pessoas. Enquanto que o simulador busca conservar a lacuna, se esquivando de qualquer critério lógico de reintegração psíquica.

Em segundo lugar, a amnésia aparece imprevistamente após algum trauma físico na cabeça, ou perturbação psíquica, como a permanência em manicômio criminal. Contudo, nos simuladores tal sintoma aparece sem nenhuma causa aparente, revelando-os. É importante salientar, no entanto, que em alguns casos de epilépticos o crime se mantém vivo na mente do infrator por alguns dias, vindo a cair no esquecimento por causa da doença. Por isso, é preciso especial cuidado para não atribuir simulação a um caso genuíno de enfermidade.

Já o infrator que mata por causa de delírio ciumento, geralmente, está sob o efeito de álcool e/ou outros psicotrópicos, e apresentam delírios e alucinações. Após o fato, retomam a consciência e apresentam remorso pelo ato, e muitas vezes apresentam profunda emoção quando mencionada a vítima. Além disso, reconhecem a magnitude fatal do ato, e aguardam, sem preocupações, o julgamento.

O simulador, no entanto, não apresenta qualquer manifestação afetuosa em relação à vítima e, embora tente simular delírios, acaba por denunciar a integridade e racionalidade de seu ato. Do mesmo modo, sua evidente preocupação e receio da condenação se manifesta em ansiedade.

E, por fim, na simulação do transtorno de estresse pós-traumático é preciso considerar a variedade de sintomas de simulação, que se modificam de acordo com o contexto da queixa e o tipo de trauma (Domingues 2012). No entanto, algumas características gerais do TEPT podem ser identificadas, facilitando a perícia.

Considerando-se o elemento temporal, o TEPT tende a aparecer nos primeiros três meses subsequentes ao evento traumático, sendo que o CID-10 estabelece o limite máximo de seis meses para o aparecimento dos 
sintomas. Os simuladores, muitas vezes, atribuem a causa do seu transtorno a um evento que aconteceu anos antes, no entanto, o TEPT de início tardio é fenômeno raro. Além do mais, o aparecimento dos sintomas justamente durante uma ação judicial é sempre motivo de suspeitas (Mendlowicz \& Berger, 2011).

Outra característica saliente do TEPT é a necessidade do padecente de evitar pensamentos, pessoas, situações e locais relacionados ao evento traumático. O simulador, sem perceber, não manifesta incômodo com determinadas condições que deveriam Ihe causar desconforto, e tendem a realizar uma representação teatral e exagerada do que deveria ser uma revivescência de um evento traumático (Mendlowicz \& Berger, 2011).

\section{Considerações finais}

A partir da pesquisa da literatura científica sobre o processo da simulação de sintomas utilizando os verbetes: "Simulação", "sintomas" e "transtornos mentais", em português e em espanhol, encontrou-se um número considerável de publicações. Contudo, com as análises dos resumos das publicações filtradas mediante os critérios selecionados, verificou-se que muitas dessas publicações tinham pouca ou nenhuma relação com a psicologia e com a simulação de sintomas e de transtornos mentais. Aponta-se, portanto, para a escassez de estudos tanto nacionais quanto internacionais na área de psicologia, tendo uma representação considerável em Portugal, especialmente na universidade de Coimbra com a realização de teses e trabalhos de conclusão de curso.

Com relação às publicações nacionais relacionadas ao comportamento de simulação, percebeuse que estavam centradas nas áreas de medicina, de fonoaudiologia, de biologia e do direito, porém ausente de publicações na psicologia. Constata-se a pouca visibilidade do tema pelos centros ou grupos de pesquisa no Brasil. Uma das razões desse número escasso se dá pelas próprias limitações da formação nos cursos de Psicologia. O presente trabalho é resultado de uma disciplina optativa de Psicologia Jurídica e a única que, em seu programa, menciona a necessidade de se discutir o tema e atentar a sua relevância nos diversos contextos em que o profissional de psicologia está inserido.

Torna-se imperativo que esse fenômeno seja mais pesquisado e que conquiste mais espaço na formação do psicólogo e na prática profissional. A literatura, aqui, utilizada aponta para um índice alto de simulação de sintomas de doenças e de transtornos mentais em vários contextos, demonstrando que essa área necessita de atenção por parte de profissionais da saúde mental, dando destaque para a avaliação psicológica, neuropsicológica e forense.

São muitas as dificuldades e desafios que surgem ao lidarmos com o fenômeno da simulação de sintomas, sendo preciso superar as limitações e avançar no conhecimento que, a cada dia, se torna mais demandado na área da psicologia. Contudo, as maiores limitações encontram-se relacionadas ao próprio desconhecimento do tema e de sua importância por parte dos profissionais da psicologia, da falta de instrumentos de avaliação psicológica forense válidos e confiáveis e logicamente, da falta de uma formação básica e de pós-graduação que prepare os alunos e profissionais para os reais problemas clínicos que enfrentarão na sua prática profissional. Por último e não menos importante, é destacável a inexistência de pesquisas empíricas sobre a simulação de sintomas no âmbito da psicologia o que é, provavelmente, uma consequência do anteriormente comentado. Neste sentido, espera-se que este artigo chame a atenção dos pesquisadores, aumentando a sua produção científica e possibilitando o desenvolvimento da área no nosso contexto.

\section{Referências}

Aliaga, A., Arch, M., García-Molina, A., \& Jarne, A. (2013). Revisión de dos instrumentos de simulación neurocognitiva y su utilidade em el contexto forense. Revista Chilena de Neuropsicologia, 8(1), 13-19. doi: $10.5839 / \mathrm{rcnp} .2013 .0801 .03$

Altavilla, E. (2007). Psicologia judiciária: o processo psicológico e a verdade judicial (Vol. 1). Coimbra: Almedina.

Andrade, F. B., \& Azevedo, R. (2006). Similaridades dos sinais e sintomas apresentados nas disfonias funcionais psicogênicas e nas disfonias com suspeita de simulação: diagnóstico diferencial. Distúrbios da Comunicação, 18(1), 63-73. Recuperado de http://revistas.pucsp. br/index.php/dic/article/view/11759

Associação Brasileira de Psiquiatria (2013). Manual diagnóstico e estatístico de transtornos mentais - DSM-5. Porto Alegre: Artmed.

Boedler, B. A., \& Rogers, J. (1989). The management of pseudohypacusis in school age children. Clinical Otolaryngol \& Allied Sciencies, 14(3), 211-215. doi: 10.1111/j.1365-2273.1989.tb00363.x

Costa, M., Espirito-Santo, H., Matreno, J., Fermino, S., \& Amaro, H. (2012). Trauma, dissociação e psicopatologia em reclusos. In $R$. Quevedo-Blasco \& V. J. Quevedo-Blasco (Orgs.), Libro de capítulos del V Congreso Internacional y X Nacional de Psicología Clínica, (pp. 491-494), Asociación Española de Psicología Conductual (AEPC), Granada: Espanha. 
Domingues, A. F. G. (2012). Escala de validade de sintomas - versão experimental (EVS-VE): estudo de validação em amostras médicolegal e comunidade (Dissertação de mestrado). Recuperado de https://estudogeral.sib.uc.pt/bitstream/10316/23257/1/Escala\%20 de $\% 20$ Validade $\% 20$ de $\% 20$ Sintomas $\% 20 \% E 2 \% 80 \% 93 \% 20$ Vers\%C3\%A30\%20Experimental\%20\%28EVS-VE\%29_Estudo\%20 de\%20valida\%C3\%A7\%C3\%A30\%20em\%20amostras\%20 m\%C3\%A9dico-legal\%20e\%20comunidade.pdf

Felipe, C. H.O. (2007). A paleontologia e a tafonomia como ferramentais para o estudo de casos de evidências de tanatose em Artrópodes fósseis (Trabalho de conclusão de curso). Centro de Ensino Superior de Juiz de Fora, Brasil. Recuperado de http://www.educadores.diaadia.pr.gov. br/arquivos/File/2010/artigos_teses/Biologia/monografia/objeto_de_ aprendizagem_paleoetologia_tafonomia_ferramentas.pdf

Gonçalves, F. M. R.V. (2012) Apanha-me se puderes: o sujeito simulador observado por uma perspectiva conceptual mista (Dissertação de mestrado). Recuperado de http://repositorio.ispa. pt/bitstream/10400.12/2307/1/15266.pdf

Jorge, R. M., \& Jorge, B. M. (2011). Simulação em lombalgia: diagnóstico e prevalência. Acta Ortopedia Brasileira, 19(4), 180-183. Recuperado de http://www.scielo.br/pdf/aob/v19n4/en_01.pdf

Mendlowicz, M. V., \& Berger, W. (2011). Simulação de transtorno de estresse pós-traumático secundário a combate em exame pericial. Jornal Brasileiro de Psiquiatria, 60(1), 67-70. Recuperado de http:// www.scielo.br/pdf/jbpsiq/v60n1/v60n1a13.pdf

Mesquita, R., \& Duarte, F. (1996). Dicionário de Psicologia. Lisboa: Plátano.

Organização Mundial de Saúde (1998). Classificação estatística internacional de soenças e problemas relacionados à saúde - CID10. Recuperado de http://livros01. livrosgratis.com.br/da000001.pdf
Paulo, R. M. M. (2012). Deteção da simulação de problemas de memória em contexto forense (Dissertação de mestrado). Recuperado de https://estudogeral.sib.uc.pt/bitstream/10316/25388/1/Dalila.pdf

Pereira, C. A. A. (2012). Estudo de "simulação" em amostra médico legal com o sims (Dissertação de mestrado). Recuperado de https://estudogeral.sib.uc.pt/bitstream/10316/23257/1/Escala\%20 de $\% 20$ Validade $\% 20$ de $\% 20$ Sintomas $\% 20 \% E 2 \% 80 \% 93 \% 20$ Vers\%C3\%A30\%20Experimental\%20\%28EVS-VE\%29_Estudo\%20 de $\% 20$ valida $\%$ C3\%A7\%C3\%A30\%20 em\%20amostras $\% 20$ m\%C3\%A9dico-legal\%20e\%20comunidade.pdf

Pinho, J. I.S.S. (2012). Testes de validade de sintomas: validação de um protocolo em amostras de adultos idosos (Dissertação de Mestrado) Recuperado de https://estudogeral.sib.uc.pt/handle/10316/23453

Sadock, B., \& Sadock, V. (2012). Manual de psiquiatria clínica: referência rápida. Porto Alegre: Artmed.

Soares, S. M. (2013). Deteção de comportamentos de esforço reduzido e exagero de sintomas numa amostra de reclusos do Estabelecimento Prisional de Coimbra (Dissertação de mestrado). Recuperado de https://estudogeral.sib.uc.pt/jspui/handle/10316/25388

Souza, R. J. (no prelo). Psiquiatria forense (Trabalho do Curso de Especialização em direito penal). Faculdade de Direito de Vitória, Vitória, ES. Brasil.

Taborda, J.G.V., Chalub, M., \& Abdala-Filho, E. (s/d). Psiquiatria forense. Porto Alegre: Artmed.

Teixeira, I. A. S. (2012). Camuflagem e mimetismo como estratégias de sobrevivência (Trabalho de conclusão de curso). Universidade do Vale do Paraíba, São José dos Campos, SP, Brasil. Recuperado de http://biblioteca.univap.br/dados/000004/00000455.pdf

\footnotetext{
${ }^{1}$ Pesquisa realizada em 02/10/2015.
} 
Diego Bezerra Rodrigues, Graduando do curso de Psicologia da Universidade Federal da Paraíba (UFPB), é Discente Pesquisador do Laboratório de Avaliação e Intervenção Clínica Forense - LAICF (UFPB/

CNPq). Endereço para correspondência: Laboratório de Avaliação e Intervenção Clínica-Forense (LAICF). Ambiente de Professor 12A.

Departamento de Psicologia. Centro de Ciências Humanas, Letras

e Artes (CCHLA). Cidade Universitária, s/n - Castelo Branco, João

Pessoa - PB, 58051-900. Telefone: (83) 996754045. E-mail: diego.shinoda.Ip@gmail.com

Géssica Almeida de Freitas, Graduanda do curso de Psicologia da Universidade Federal da Paraíba

(UFPB). E-mail: g.almeida1992@gmail.com

Arethusa Eire Moreira de Farias, Mestre em Geografia pela Universidade Federal da Paraíba (UFPB), é Graduanda do curso de Psicologia da Universidade Federal da Paraíba

(UFPB). E-mail: arethusa_hot@yahoo.com.br

Carmen Amorim-Gaudêncio, Doutora em Psicologia pela Universidade Complutense de Madri (UCM), Espanha, é Professora do Departamento de Psicologia na Universidade Federal da Paraíba (UFPB) e Coordenadora do Laboratório de Avaliação e Intervenção Clínica Forense - LAICF (UFPB/CNPq). E-mail: camorimg@gmail.com 